\title{
Health Problems in Zvimba Rural and Communal Areas in Zimbabwe
}

\author{
Takudzwa Mhandu $^{1}$ Thandi F. Khumalo ${ }^{2}$ Maxwell C.C. Musingafi ${ }^{3 *}$ \\ 1.Great Zimbabwe University, Department of Demography and Population Studies, Faculty of Social Sciences \\ 2.University of Eswatini, Department of Sociology and Social Work, Faculty of Social Sciences \\ 3.Zimbabwe Open University, Department of Development Studies, Faculty of Applied Social Sciences
}

\begin{abstract}
This study was carried out to determine people's health problems in Zvimba district in Mashonaland West Province. The research employed the survey research design to solicit data since it was found to be the most appropriate for this study as it was capable of capturing the respondents' views towards health issues in Zvimba district fast enough to meet both the time frame and the demands of the study. It involved 189 participants in an easily definable geographical area. These respondents comprised 135 communal dwellers who visited clinic or hospital the same day one of the researchers passed through the clinic or the hospital collecting data for the study, plus 54 professional health workers who accepted to participate in the study. The study used questionnaires and interviews for the collection of data. Research results showed that malaria and diarrhoea were the most prevalent diseases with the highest frequency rates among other diseases. The study recommends increase in the number of clinics, availability of low cost public transport, upgrade of road network links and community engagement in health awareness programmes.
\end{abstract}

Keywords: People, health, health problems, rural, communal, Zvimba, Zimbabwe

DOI: $10.7176 / \mathrm{DCS} / 9-4-09$

Publication date: April $30^{\text {th }} 2019$

\section{Orientation}

This study sought to investigate people's health problems in Zvimba district, Mashonaland West Province, Zimbabwe. The study was confined to a single district, Zvimba district in Mashonaland west province. The district is one of the top health care providers with more health care centres than other rural districts in Zimbabwe (Mhandu and Chazireni, 2016; Chazireni and Harmes, 2013). Zvimba district is in central northern Zimbabwe. bordered by Guruve district to the north, Mazowe district to the east, the city of Harare to the southeast, Chegutu district to the south, Kadoma district to the southwest and Makonde district to the west and northwest. Its capital, Murombedzi, is located about 110 kilometres west of Harare and 48 kilometres south of the town of Chinhoyi.

With a total population of 263,020 (ZIMSTATS, 2014), Zvimba has a large population which depends upon small scale subsistence farming of mainly cereals and a variety of cash crops like tobacco, beans and potatoes. These farming activities are promoted by the presence of rich fertile soils of intrusive and extrusive volcanic origins and prevalence of perennial water sources like Darwendale Dam where fishing also takes place. The district lies within the savannah climate with an annual reliable rainfall of not less than $850 \mathrm{~mm}$ and an average summer temperature of 26 degrees Celsius more suitable for a variety of commercial and subsistence farming activities. Most of the economically active population is employed in large scale tobacco commercial farms and chrome mining activities along parts of the Great Dyke which pass through the district. 


\section{Zvimba District}

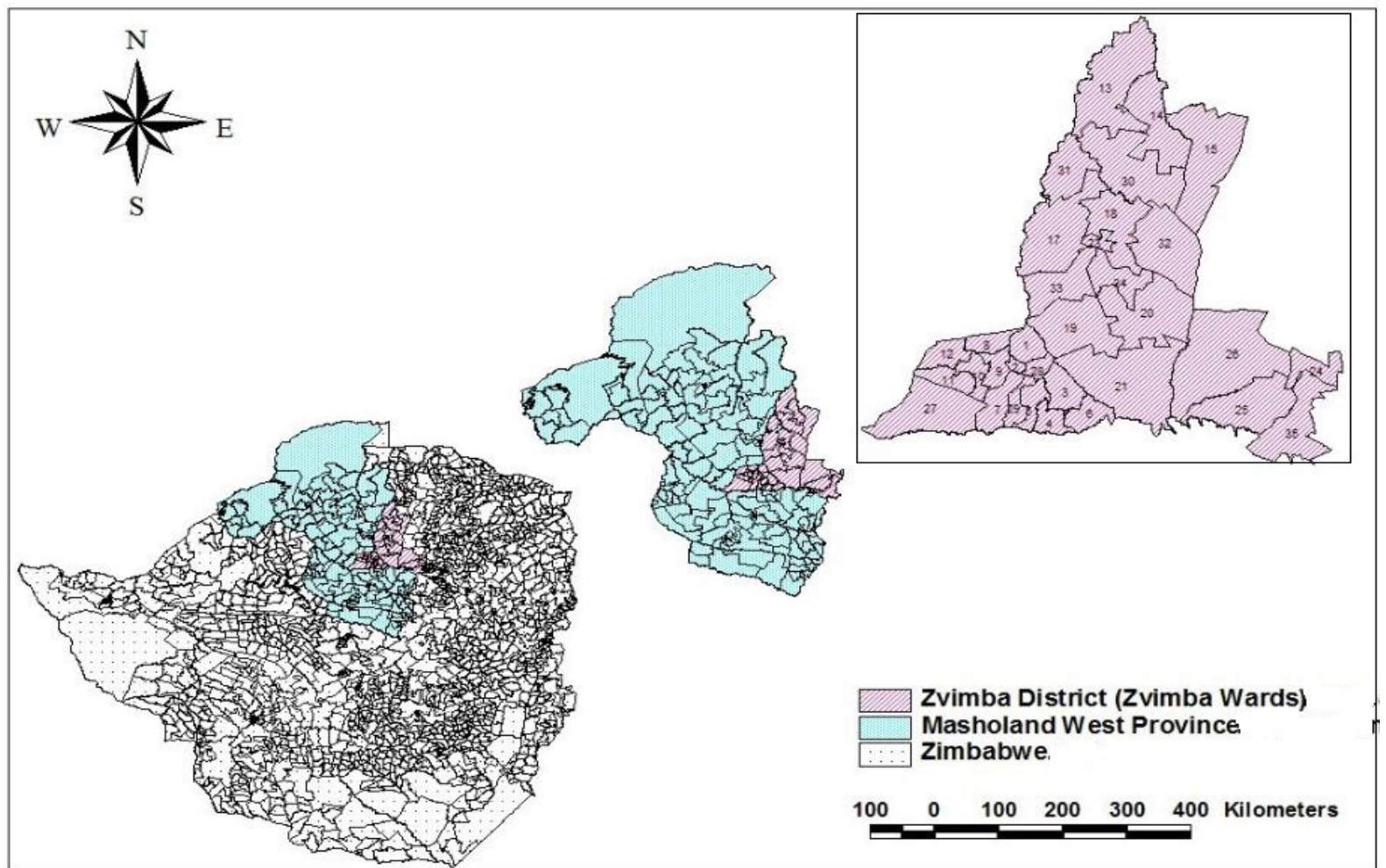

Fig. 1: The Study Area Map (Source: Research Data)

\section{Methodology}

The research used instruments like questionnaires, interviews and observations. Statistical tables, graphs, charts, trends and percentages were used to quantify and compare data on the most common type of problems, challenges as well as the frequently requested solutions to the people's problems.

\section{Gender distribution in Zvimba district,}

The respondents consisted of 77 females and 58 males translating to $57 \%$ females and $43 \%$ males? This means that at the time of the study, more females visited the clinics and hospitals than their male counterparts in Zvimba District. They were either directly seeking medical health or being responsible with the sick whom they accompanied to the clinic for medical attention. This is presented in a graphical form below. It is vital to note that Zimbabwean population consists of more women than men. Hence, the proportion can be a direct effect of that discrepancy. Woman are also more involved in taking care of the sick than men especially considering our cultural set up. Therefore, in clinics and hospitals where the sick are taken to such environments- it can be by such reasons that females can dominate those environments. Zvimba is a rural area which means most economically active men would have migrated to the nearby busy capital city Harare and the tourist town of Chinhoyi leaving women behind. 


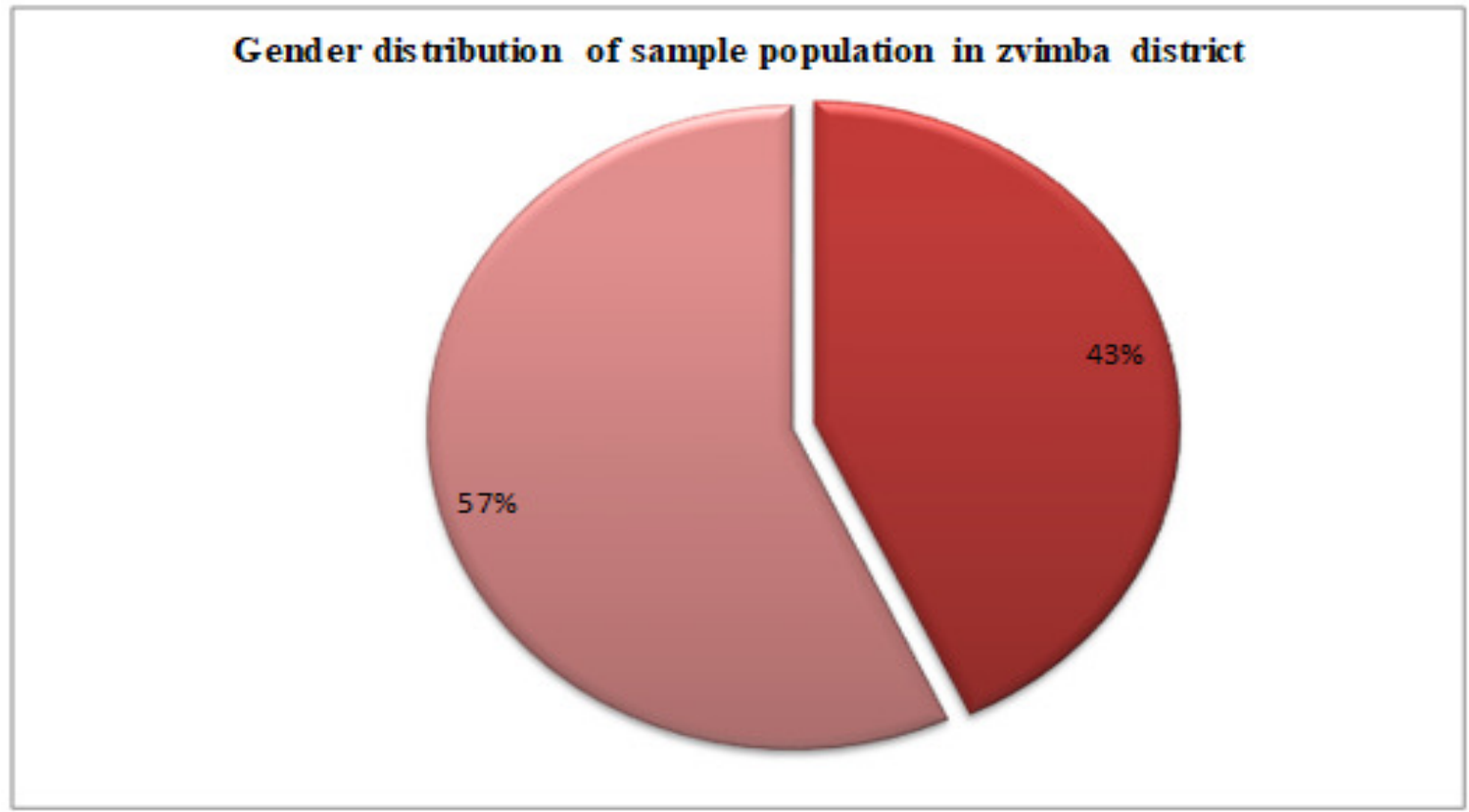

Fig.2: Gender distribution of respondents: (Source: Research Data)

\section{Age groups of sampled population in Zvimba district}

Extracted information concerning age groups of respondents revealed the information exhibited in Fig 3. The graph reveals that the highest number of people who visited clinics and hospitals in Zvimba area were between the age group of 26-35 years old. This was followed by the 36-45 years age group. The least group of people or respondents who visited the medical centres were the 56 years group. This can be because the 26-35 age group were more vulnerable to disease as they were highly involved in sexual activities especially with the poorly performing Zimbabwean economy. Therefore, most people die before reaching old age. The rate of outmigration in Zimbabwe is generally high and thus Zvimba district is not an exception. It is also affected by high outmigration of highly qualified and experienced people who have reached the apex of their career. This deprives the above 46 years of their population.

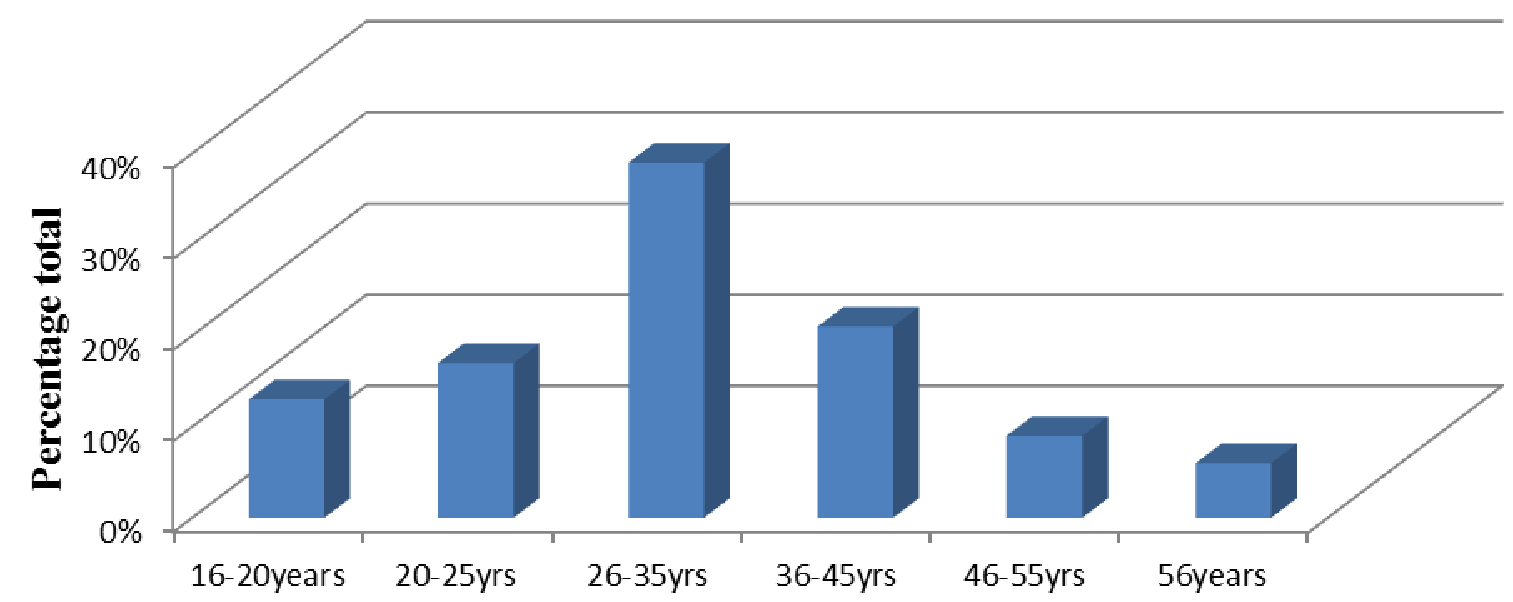

Age groups of respondents

Fig 3: Percentage of ages of respondents who visit clinics and hospitals in Zvimba District: (Source: Research Data) 
5. Levels of education of Zvimba district habitants who responded to questionnaires.

Fig 4 shows that the highest number of the Zvimba population have ordinary level certificates at $44 \%$ followed by Zimbabwe Junior certificates (ZJC) holders at $20 \%$. The results directly depict that Zimbabwean education's basic level is ordinary level (' $\mathrm{O}$ ' level). It is mandatory in Zimbabwe for all learners to reach ' $\mathrm{O}$ ' level. Therefore, respondents were literate enough to understand health issues. Thus results from this study can be regarded as valid and a true reflection of the situation on the ground.

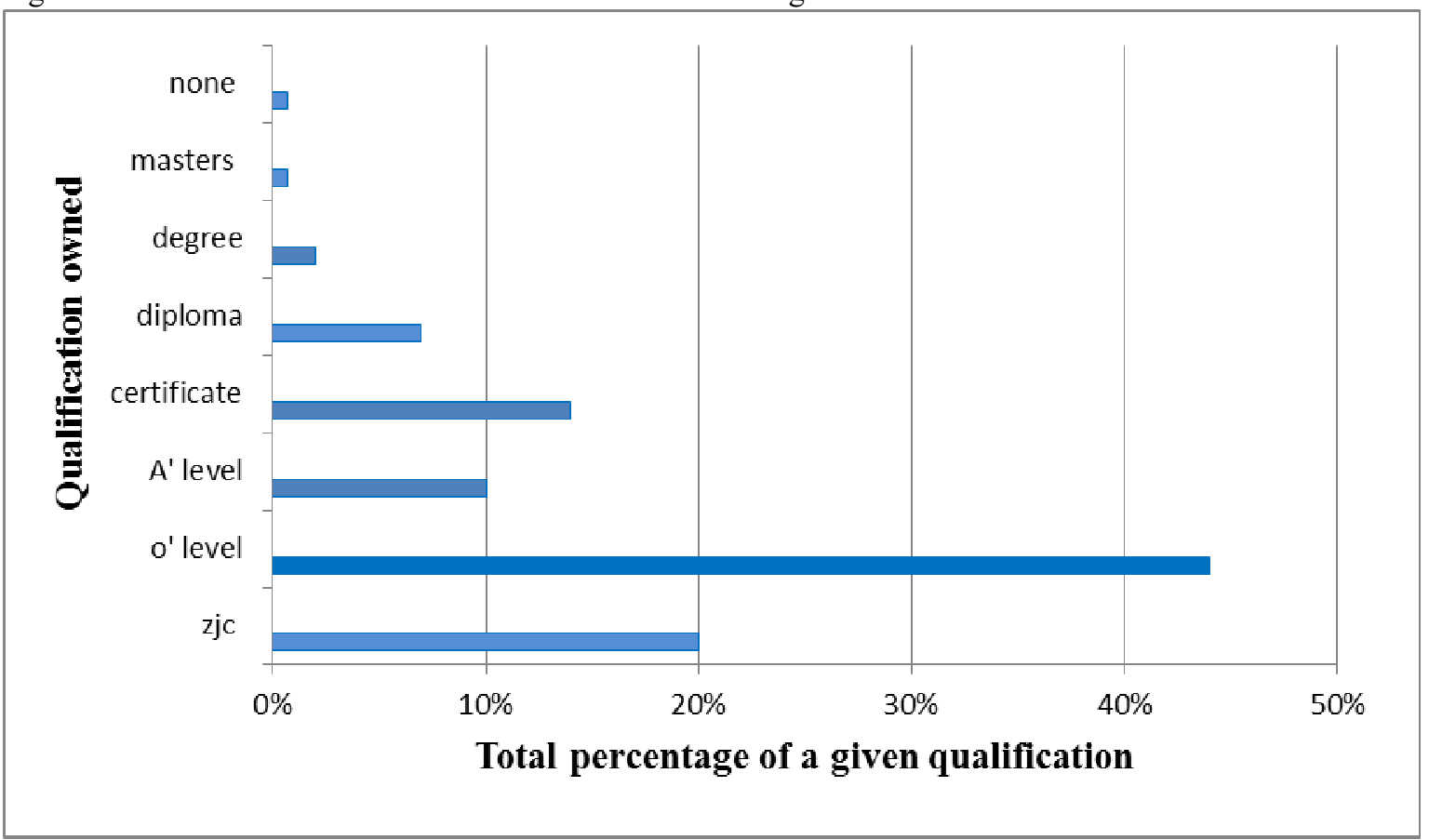

Fig. 4: levels of education of respondents: (Source: research data)

6. The medical assistance which people in Zvimba district received from government and NonGovernmental Organisations

Medical assistance respondents received from government or NGOs:

- mosquito nets from NGOs (frequency 127/135 (94\%);

- water treatment drugs and water pills (frequency 82/135 (61\%);

- $\quad$ clinics and hospitals; (frequency 23/135 (17\%);

- $\quad$ free treatment (frequency $13 / 135(9.6 \%)$;

- $\quad$ ARVs (frequency 41/135 (30\%);

- boreholes (frequency 17/135 (13\%);

- $\quad$ counselling services from NGOs organisations (frequency 2/135 (1.4\%);

- free condoms (frequency $16 / 135(12 \%)$;

- free vaccination of children; (frequency 10/135 (7.4\%);

- $\quad$ oral sachets for diarrhoea from NGOs (frequency 52/135 (39\%); and

- $\quad$ maize for food provision periodically (frequency $4 / 135(3 \%)$.

The fact that the highest percentage of respondents visited health centres for mosquito nets and water treatment drugs reflects that this area could be malaria and other waterborne disease infested.

7. Occupation of sampled population who visited clinics and hospitals in Zvimba district.

Table 1: Occupation of Respondents in Zvimba District: (Source: Research Data)

\begin{tabular}{|l|l|}
\hline Occupation & Frequency or percentage of respondents \\
\hline Farmers & $39(29 \%)$ \\
\hline Civil servants & $24(18 \%)$ \\
\hline Domestic workers & $34(25 \%)$ \\
\hline Mining & $10(7 \%)$ \\
\hline Buying and selling & $23(17 \%)$ \\
\hline Private employment & $7(5 \%)$ \\
\hline
\end{tabular}




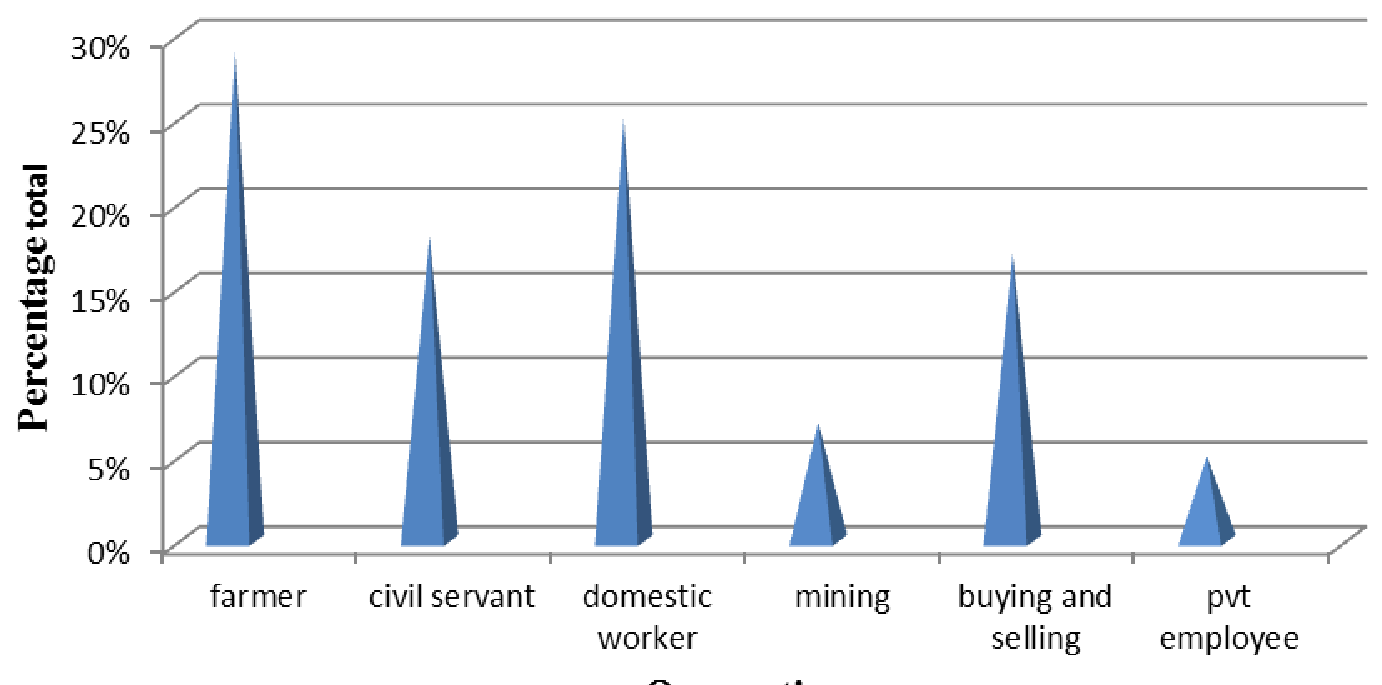

Occupation

Fig. 5: Occupation of respondents who visited clinics and hospitals in Zvimba district: (Source: Research Data)

Most people in Zvimba district are involved in farming activities since the district is a farming dominated area. The second largest occupation is domestic workers with $25 \%$ a reflection of low order jobs dominating the district.

8. Average distance travelled by Zvimba district population to seek medical attention: The table below shows the results.

Table 2: Average distance travelled by Zvimba dwellers to the nearest clinic or hospital: (Source: Research Data)

\begin{tabular}{|l|l|}
\hline Average distance & Frequency and percentage of respondents \\
\hline $1-2 \mathrm{~km}$ & $11(8 \%)$ \\
\hline $3-4 \mathrm{~km}$ & $31(23 \%)$ \\
\hline $5-6 \mathrm{~km}$ & $32(24 \%)$ \\
\hline $7-8 \mathrm{~km}$ & $26(19 \%)$ \\
\hline $9-10 \mathrm{~km}$ & $21(15 \%)$ \\
\hline $11-12 \mathrm{~km}$ & $9(6 \%)$ \\
\hline $13-14 \mathrm{~km}$ & $9(6 \%)$ \\
\hline
\end{tabular}

From the above results it is evident that the average distance travelled by most Zvimba district dwellers is between 6-9 kilometres. The impact of such a distance is that the vulnerable age groups like the young, the aged, the seriously ill and the disabled might not have been visiting medical centres. Yet they required frequent health care services. These vulnerable groups could not sustain long walks in an area where transport was scarce. Most of those who visited medical centres traveled on foot to reach the nearest clinic or hospital. Thus, most cases of poor health or disease occurrence were not given immediate attention because of the distance problems.

9. Common problem diseases for households in Zvimba district.

Table 3 shows that malaria, diarrhoea, headaches, colds and flu dominated the list of common diseases in Zvimba district. This is a malaria prone area. Also, it was evident that waterborne diseases were the biggest problem in the area. These waterborne diseases were a result of poor hygiene. Colds and flu were likely to be a result of prolonged exposure working in tobacco fields and bans. 
Table 3: Household problem diseases in Zvimba district: (Source: Research Data)

\begin{tabular}{|l|l|l|}
\hline Problem disease & Frequency & $\mathbf{\%}$ \\
\hline Malaria & 104 & 77 \\
\hline TB & 38 & 28 \\
\hline Diarrhoea & 78 & 58 \\
\hline Syphilis & 4 & 3 \\
\hline HIV/AIDS & 28 & 20.7 \\
\hline Colds and flu & 51 & 38 \\
\hline Measles & 5 & 3.7 \\
\hline Headaches & 64 & 47 \\
\hline Typhoid & 48 & 35.5 \\
\hline Bilharzia & 11 & 8 \\
\hline Cancer & 16 & 12 \\
\hline Dysentery & 23 & 17 \\
\hline Sleeping sickness & 3 & 2.2 \\
\hline Fever & 2 & 1.5 \\
\hline Heat rash & 2 & 1.5 \\
\hline
\end{tabular}

10. The form of transport used to reach the nearest clinic

As shown in Table 4 below, the highest number of sampled population traveled on foot to reach the nearest health care service centre, followed by use of scotch carts, bicycles, cars and public transport in that order. This clearly explains the poverty levels in the district. People are highly poor as those with potential to develop the area have migrated to big cities like Harare or even beyond Zimbabwean borders. With the economy at one of its lowest ebb the majority of youth and able bodied had migrated from the district looking for means to survive the harsh economic environment in the country.

Table 4 is a summary of the means of transport in Zvimba district and their rate of use for travel to medical centres in the area.

Table 4: Mode of transport used by respondents to reach the clinic or hospital: (Source: Research Data)

\begin{tabular}{|l|l|}
\hline Mode of transport used & Percentage frequency $\mathbf{( \% )}$ \\
\hline Using own car & 3 \\
\hline Bicycle & 17 \\
\hline Scotch carts & 28 \\
\hline Foot & 39 \\
\hline Commuter omnibus & 9 \\
\hline Failure to respond & 3 \\
\hline Total & 100 \\
\hline
\end{tabular}

11. Health service provision problems experienced in Zvimba district.

The health service provision problems in Zvimba were as in Table 5:

Table 5: Health service provision problems in Zvimba district: (Source: Research Data)

\begin{tabular}{|l|l|}
\hline Health service provision problems & Frequency and percentage \\
\hline Lack of food & $2(0 \%)$ \\
\hline Shortage of drugs & $64(47 \%)$ \\
\hline Shortage of ambulances & $71(53 \%)$ \\
\hline Shortage of nurses and doctors & $27(20 \%)$ \\
\hline Shortage of water & $4(3 \%)$ \\
\hline
\end{tabular}

Shortage of ambulances was listed as the major service provision problem in Zvimba district with $53 \%$ frequency. This was followed by shortage of drugs. The economic situation facing Zimbabwe was to blame for these problems. Most drugs used in Zimbabwe were imported from foreign countries mainly European and North-American countries. The resultant effect was that most clinics and hospitals operated with less than minimum drugs. The ambulances used to be maintained by CMED but because of economic meltdown and brain drain, most engineers and technicians left the country for better wages. This resulted in most vital sectors of government being left vulnerable with the health sector being the most affected.

Other health problems affecting people in Zvimba district included high blood pressure, depression and pollution. The nature of pollution is mainly land pollution emanating from use of bush toilets in densely populated areas like close to growth points and community shopping centres. 


\section{Health awareness programmes in the community}

Health personnel workers on disease control and health issues never educated the majority of respondents. This could explain the high cases of diarrhoea and other diseases that are mainly as a result of poor hygiene. Most diseases mentioned by the sampled population could be avoided by practising good hygiene at homestead, but that information seemed to be lacking so much that the rural dwellers were at risk of infectious diseases.

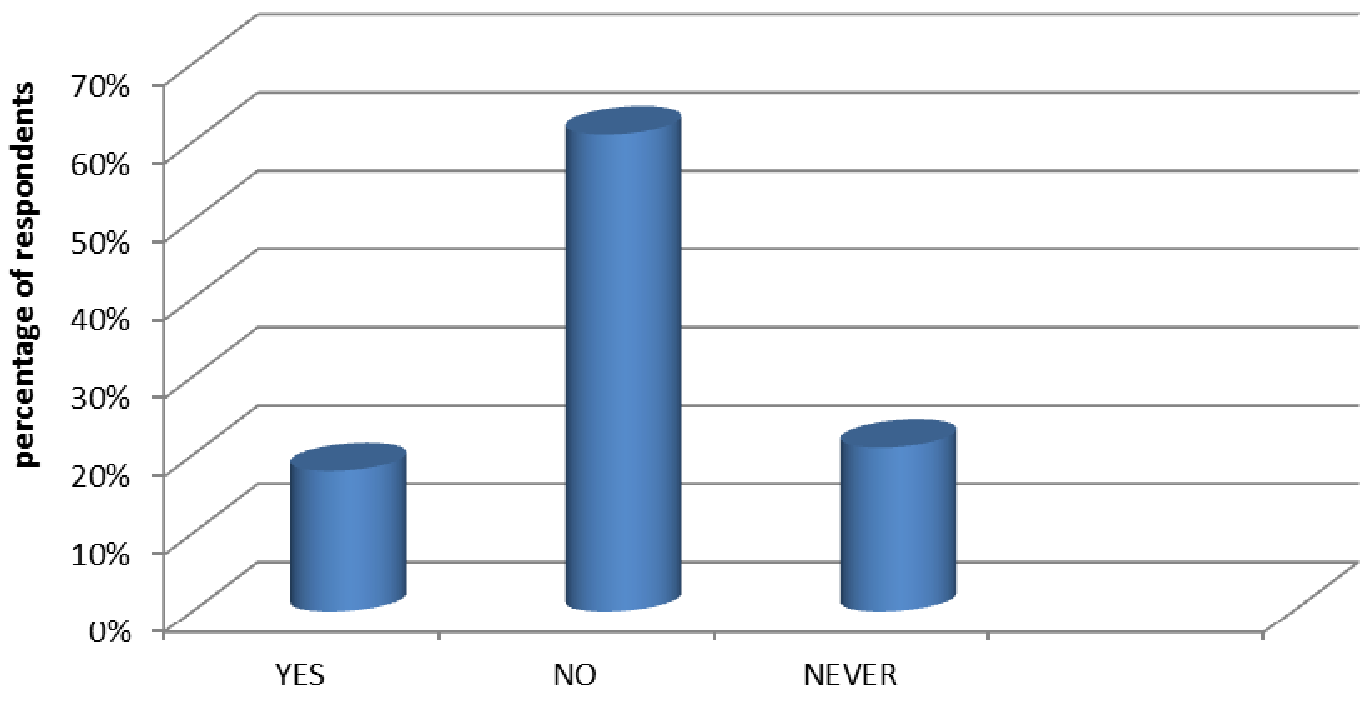

Fig. 6 Responses to whether health awareness programmes were conducted in the community: (Source: Research Data)

\section{Conclusion}

In this study it was established that people's health problems in Zvimba district were mainly as a result of disease problems namely malaria, diarrhoea, skin problems, dysentery, headaches and several others. The main disease problems were accelerated by lack of environmental health awareness which should be conducted by environmental health officers accompanied by nurses and area doctors. Poor linking roads in the region were exacerbating lack of transport, especially lack of private public transporters. This gave patients no option except to walk longer distance to seek medical attention. Despite the area being adequately staffed, there were drugs shortages in hospitals and clinics. Patients were forced to get drugs from expensive pharmacies. Most of them could not afford the drugs from pharmacies. Although all clinics had professional nurses, they were not enough considering the number of people who visited these centres to seek medical attention.

\section{Recommendations}

In light of the above research findings, it is recommended that:

- more environmental health officers be dispatched to the community to carry out health awareness programmes to equip community dwellers with necessary knowledge to avert diseases and teach them about hygiene issues;

- $\quad$ the government and Non-Governmental Organisations should help with the provision of ambulances to clinics and hospitals to speed up the movement of sick people as a way of reducing mortality rate;

- roads should be improved and constantly repaired to attract private transporters to operate in the region (increase in the number of private transporters forces bus fares to be low making it affordable to the rural peasants in Zvimba district who are mostly farmers and domestic workers earning very low income);

- mobile clinics should be introduced to cut short the distance travelled by people in the periphery areas;

- provision of food stuffs such as maize is necessary since the area experienced sizeable cases of malnutrition;

- $\quad$ an adequate number of nurses should be placed in clinics and hospitals so that there is quick service provision and less delays; and

- administration work should be precisely done by clerks and bookkeepers not nurses to improve speed of health delivery system 


\section{Reference.}

Chazireni E, Harmse A.C. (2013). People's state of health in Zimbabwe; A spatial perspective. International Journal of Research in Economics \& Social Sciences 3 (1). Pp 2249-7382.

Gwimbi, P. and Dirwai, C. (2003). Research Methods in Geography and Environmental Studies: Module GED302. Zimbabwe Open University. Harare.

Leedy, B. (1993). Research Methods for Educationists. Third edition. Greyham Ltd. New Delhi.

Mhandu, T. and Chazireni, E. (2016). The Spatial Dimension of Health Service Provision in Mashonaland West Province, Zimbabwe. Scholars Journal of Applied Medical Sciences. 4 (1). Pp 201-204.

Ministry of Health and Child Welfare (2004) Needs Assessment for the Health Sector in Ministry of Health and Child Welfare. National Health Profile. Harare. Government of Zimbabwe.

Osika (2011) Zimbabwe Health System Assessment January 2011. A review by the United States Agency for International Development. It was prepared by John Osika, Danielle Altman, Leah Ekbladh, Itamar Katz, Ha Nguyen, Josh Rosenfeld (Abt Associates Inc.), Taylor Williamson (RTI International), and Sam Tapera (Best Practices, Ltd.) for Health Systems 20/20 Project.

Wisker, B. (2009) research methods in humanities, Goddard, New York

Zimbabwe National Statistical Agency; 2012.Published national reports of the 2012 population. 